\title{
Modeling conduit choice for valve-sparing aortic root replacement on biomechanics with a 3-dimensional-printed heart simulator
}

Michael J. Paulsen, MD, ${ }^{\mathrm{a}}$ Patpilai Kasinpila, MD, ${ }^{\mathrm{a}}$ Annabel M. Imbrie-Moore, BS, ${ }^{\mathrm{a}, \mathrm{b}}$ Hanjay Wang, MD, ${ }^{\mathrm{a}}$ Camille E. Hironaka, BS, ${ }^{a}$ Tiffany K. Koyano, BS, ${ }^{a}$ Robyn Fong, BS, ${ }^{\text {a }}$ Peter Chiu, MD, ${ }^{a}$ Andrew B. Goldstone, MD, PhD, ${ }^{a}$ Amanda N. Steele, MS, ${ }^{\mathrm{a}, \mathrm{c}}$ Lyndsay M. Stapleton, MS, ${ }^{\mathrm{a}, \mathrm{c}}$ Michael Ma, MD, ${ }^{\mathrm{a}}$ and Y. Joseph Woo, MD ${ }^{\mathrm{a}, \mathrm{c}}$

\section{ABSTRACT}

Objective: The optimal conduit for valve-sparing aortic root replacement is still debated, with several conduit variations available, ranging from straight tubular grafts to Valsalva grafts. Benefits of neosinus reconstruction include enhanced flow profiles and improved hemodynamics. Curiously, however, some clinical data suggest that straight grafts may have greater long-term durability. In this study, we hypothesized that straight tubular grafts may help maintain the native cylindrical position of the aortic valve commissures radially, resulting in preserved leaflet coaptation, reduced stresses, and potentially improved valve performance.

Methods: Using 3D printing, a left heart simulator with a valve-sparing root replacement model and a physiologic coronary circulation was constructed. Aortic valves were dissected from fresh porcine hearts and reimplanted into either straight tubular grafts $(n=6)$ or Valsalva grafts $(n=6)$. Conduits were mounted into the heart simulator and hemodynamic, echocardiographic, and high-speed videometric data were collected.

Results: Hemodynamic parameters and coronary blood flow were similar between straight and Valsalva grafts, although the former were associated with lower regurgitant fractions, less peak intercommissural radial separation, preserved leaflet coaptation, decreased leaflet velocities, and lower relative leaflet forces compared with Valsalva grafts.

Conclusions: Valsalva grafts and straight grafts perform equally well in terms of gross hemodyanics and coronary blood flow. Interestingly, however, the biomechanics of these 2 conduits differ considerably, with straight grafts providing increased radial commissural stability and leaflet coaptation. Further investigation into how these parameters influence clinical outcomes is warranted. (J Thorac Cardiovasc Surg 2019;158:392-403)

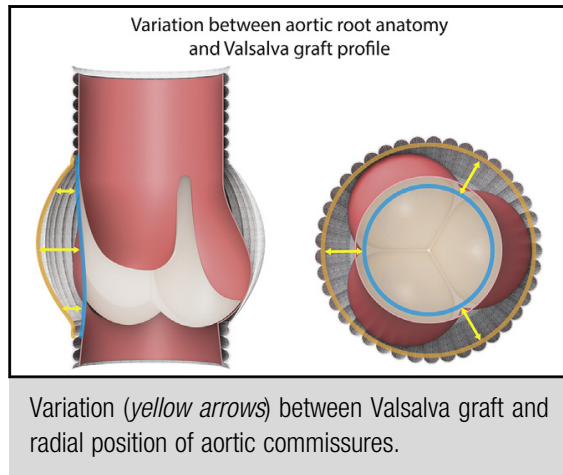

\section{Central Message}

Straight grafts maintain the radial position of the aortic valve commissures in their native cylindrical conformation, preserving leaflet coaptation and decreasing regurgitation, cusp velocities, and forces.

\section{Perspective}

Valve-sparing root replacement is an effective treatment for aortic root aneurysms, although the ideal conduit is unknown. While neosinus reconstruction is believed to generate more physiologic flow profiles and optimized hemodynamics, it does not appear to increase longterm clinical durability over straight grafts. Ex vivo testing was used to provide a mechanistic comparison and demonstrated decreased cusp velocities, forces, and regurgitation in straight grafts.

See Commentaries on pages 404 and 406.
From the Departments of ${ }^{\mathrm{a}}$ Cardiothoracic Surgery, ${ }^{\mathrm{b}}$ Mechanical Engineering, and ${ }^{\mathrm{c}}$ Bioengineering, Stanford University, Stanford, Calif.

This work was funded by the National Institutes of Health (R01HL089315-01 to Y.J.W.), the American Heart Association (17POST33410497 to M.J.P., 18POST33990223 to H.W.), by the National Science Foundation Graduate Research Fellowship Program (to A.M.I.) and by a Stanford Graduate Research Fellowship (to A.M.I.)

Received for publication July 10, 2018; revisions received Oct 7, 2018; accepted for publication Oct 19, 2018; available ahead of print Feb 10, 2019.

\footnotetext{
Address for reprints: Y. Joseph Woo, MD, Department of Cardiothoracic Surgery, Stanford University, Falk Cardiovascular Research Building CV-235, 300 Pasteur Dr, Stanford, CA 94305-5407 (E-mail: joswoo@stanford.edu). 0022-5223

Copyright $(2018$ by The American Association for Thoracic Surgery. Published by Elsevier Inc. This is an open access article under the CC BY-NC-ND license (http:// creativecommons.org/licenses/by-nc-nd/4.0/). https://doi.org/10.1016/j.jtcvs.2018.10.145
} 


$$
\begin{aligned}
& \text { Abbreviations and Acronyms } \\
& \begin{array}{ll}
\text { 3D } & =3 \text { dimensional } \\
\text { EOA } & =\text { effective orifice area } \\
\text { LVOT } & =\text { left ventricular outflow tract } \\
\text { SG } & =\text { straight graft } \\
\text { TEE } & =\text { transesophageal echocardiography } \\
\text { VG } & =\text { Valsalva graft } \\
\text { VSARR } & =\text { valve-sparing aortic root replacement }
\end{array}
\end{aligned}
$$

Scanning this QR code will take you to the article title page to access supplementary information.

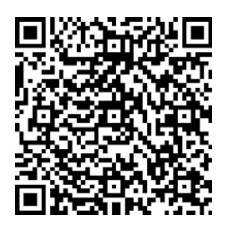

The development of valve-sparing aortic root replacement (VSARR) with the reimplantation and remodeling techniques has generated a transformational shift in the management of aortic root aneurysms. Their common aim is to restore aortic geometry by correcting aortic root and annular dilation, while preserving the native aortic valve. ${ }^{1}$ Whereas the remodeling technique is believed to better preserve native valvular mechanical patterns and aortic root distensibility, ${ }^{2}$ reimplantation of the valve might be superior in counteracting further annular dilatation - this is especially essential in young patients with inherited connective tissue disorders. ${ }^{3}$ This disparity is likely due to inevitable alterations, however minute, of the relative geometries between the annulus, aortic cusps, sinotubular junction, and sinuses of Valsalva in the root replacement technique with a straight Dacron conduit.

Described in the 1960s, and later supported by multiple studies, the flow vortices created by the sinuses of Valsalva are thought to be critical in maintaining ideal aortic hemodynamics, encouraging smooth valve closure and optimal coronary blood flow. ${ }^{4-7}$ Thus, in an attempt to recreate the native geometry, multiple iterations of the original David I procedure using a straight graft (SG) have been developed-coined the David II, III, IV, V, and Vs-mod operations-many of which aim to create physiologic neosinuses by modifying the Dacron graft. ${ }^{8-10}$

In 2000, Dr De Paulis and colleagues introduced a novel conduit, known as the Valsalva graft (VG), with a preformed billowed skirt aimed to mimic the native sinuses after valve reimplantation. ${ }^{11,12}$ Based on a multitude of in vivo studies, it is believed that recreating the sinuses may improve coronary hemodynamics, reduce anastomotic stresses, and enhance flow profiles. ${ }^{11,13}$ Although recent long-term follow-up by Dr De Paulis' group showed results comparable with those of Dr David and colleagues in terms of 10-year survival, the SG interestingly had better freedom from reoperation at 10 years. The longest reported followup with the VG is 13 years, with freedom from reoperation of $90.1 \pm 4.3 \%$; for the SG, follow-up out to 20 years with $96.9 \pm 1.3 \%$ freedom from reoperation is reported. ${ }^{14,15}$ Other studies using the VG with long-term follow-up, including a multi-institutional, multisurgeon trial, reported freedom from reoperation between $89 \%$ and $94 \%$ at 4 years. ${ }^{16-19}$ Because of various modifications of the David procedure using SGs (with or without plication, necking graft down, etc) or switching to the VG midway through the study period, it is difficult to compare isolated repairs using unmodified SGs versus those with neosinuses added because these are typically grouped together in the same category of reimplantation (vs remodeling, which most of these studies sought to compare). Studies using cylindrical grafts (with or without modification) report 5-year freedom from reoperation between $91 \%$ and $98 \%$ and those reporting exclusive use of the David I technique (SG without modification) report $91 \%-97 \%$ freedom from reoperation at 5 years. $^{20-24}$ Making comparisons between this assortment of studies with varying conditions is nearly impossible, so we sought to compare these 2 grafts in a controlled ex vivo environment to elucidate the mechanisms behind this disparity.

Multiple factors might account for the disparity between VG and SG durability. First, VGs are limited to predetermined, fixed proportions, which might not match aortic root anatomy for individual patients. ${ }^{8,25}$ Furthermore, the VG's neosinuses are spherical in shape, which may not replicate the trilobed native root geometry, and might result in distortion of the fibrous coronet-shaped surgical annulus where the leaflets insert at the anatomic ventriculoaortic junction. ${ }^{26}$ Although the VG reasonably matches native root and sinus geometry longitudinally, transversely there exists a variation between the trefoil-shaped aortic root and spherical VG (Figure 1, A). As shown, the radius of curvature passing along the commissures is substantially smaller than the outer extent of the sinuses and VG, creating a mismatch between aortic valve anatomy and the graft. Even with the top of the commissural posts secured to the distal cylindrical portion of the VG and annulus secured proximally, the leaflet hinge region along the mid and lower portion of the commissural posts, which should be maintained in a cylindrical configuration, does not precisely follow the VG profile (Figure 1, B). We hypothesize that this variation may deform the radial position of the aortic valve commissures outward, whereas maintaining the native cylindrical conformation using a straight tubular graft could help preserve leaflet coaptation and reduce leaflet stresses. 

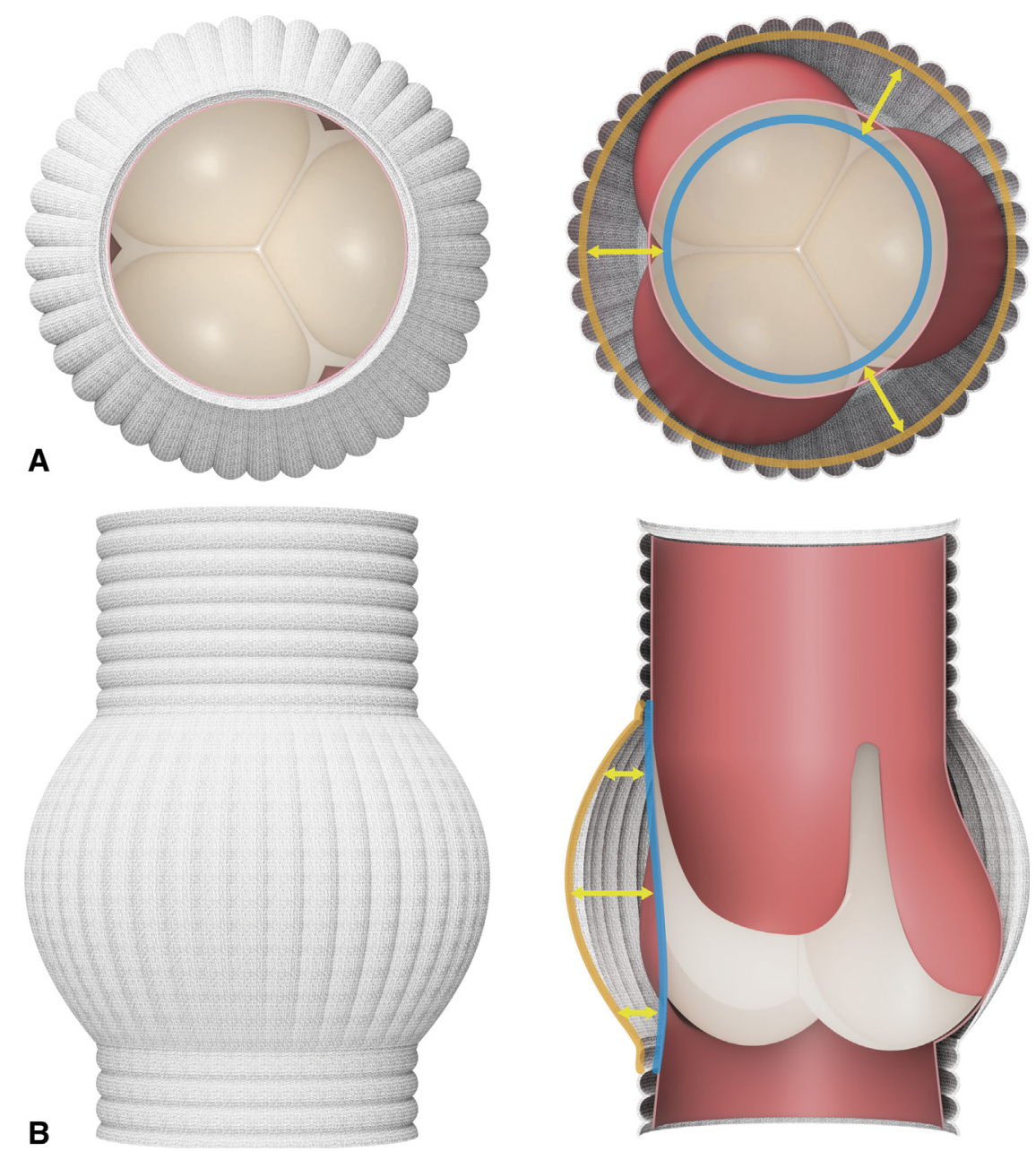

FIGURE 1. A, Transverse view of the aortic root within a Valsalva graft with cutaway showing variation (yellow arrows) between the radial position of the commissures (blue circle) and the graft/sinuses (orange circle). B, Valsalva-style graft in longitudinal view with cutaway showing, despite appropriately matching graft profile with the aortic annulus and sinotubular junction, the midportion of the commissures (blue line) do not align with the Valsalva graft profile (orange line), causing the graft and commissures to exert radial forces on one another (yellow arrows).

In our study, we designed a custom 3-dimensional (3D) - printed ex vivo left heart simulator adapted for a VSARR model to compare the effects of straight and commercially available VGs. Specifically, we assessed aortic root hemodynamics as well as aortic valve biomechanics using high-speed videometry, echocardiographic analysis, and direct electromagnetic measurements of fluid dynamics.

\section{METHODS}

\section{Left Heart Simulator Design and Validation}

We designed and prototyped our heart simulator using additive manufacturing (Carbon M2, Carbon, Redwood City, Calif) and machining technologies (Figure 2,A). The 3D-printed left heart was mounted to a programmable linear pump (Superpump with ViVitest software; ViVitro, Victoria, British Columbia, Canada), which generates physiologic ventricular waveforms. The simulator was outfitted with ventricular, aortic, left atrial, and coronary pressure transducers (Utah Medical, Midvale, Utah), electromagnetic flow probes in the aortic and mitral positions (Carolina Medical Electronics, East Bend, NC), and a coronary flowmeter (Transonic Systems, Ithaca, NY). Normal saline $(0.9 \%)$ served as our test fluid to ensure accurate flow meter transduction.

A viscoelastic impedance adapter (ViVitro) with 2 compliance chambers $\left(0-120 \mathrm{~mL}\right.$ source, $0-60 \mathrm{~mL}$ output) and a $200 \mathrm{dyne} \cdot \mathrm{s} / \mathrm{cm}^{5}$ fixed resistor, was used to reduce noise and generate more physiologic waveforms. We used $100 \mathrm{~mL}$ and $50 \mathrm{~mL}$ of air in the source and output chambers, respectively, to model characteristic resistance and compliance. Aortic compliance chambers ( $1000 \mathrm{~mL}$ air volume) allowed tuning of the aortic pressure waveform. Fluid from the venous reservoir passes through the mitral flow meter, enters the left atrium, and passes through a disc valve in the mitral position (ViVitro) into the ventricle. As the piston pressurizes the ventricle, fluid ejects through the left ventricular outflow tract (LVOT), aortic flow meter, and valved conduit within the aortic root compliance chamber before entering the aortic compliance assembly. Because grafts possess intrinsic compliance, the aortic root chamber was open to the atmosphere to mimic in vivo conditions. A heat exchanger kept fluid at $37^{\circ} \mathrm{C}$ (Polystat; Cole-Parmer, Vernon Hills, Ill). Fluid passes through a peripheral resistance throttle-valve (ViVitro) before returning to the venous reservoir. 


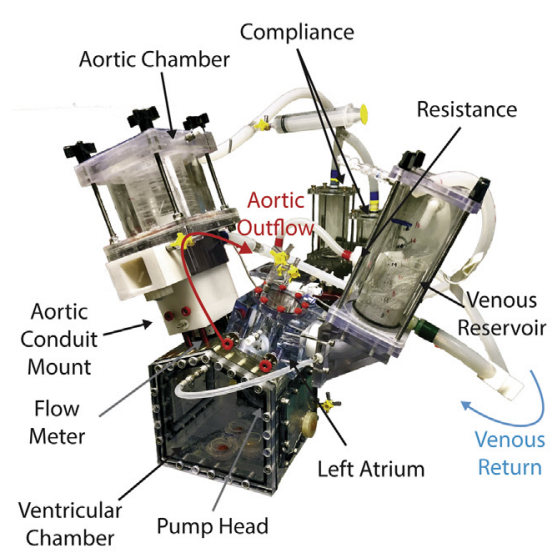

A
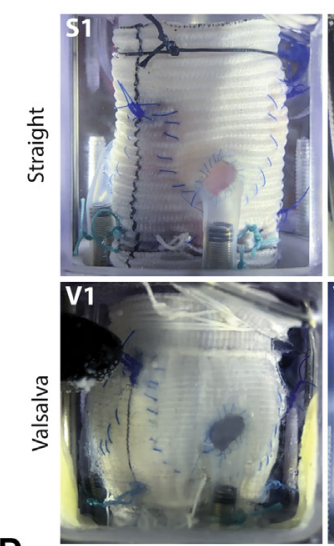
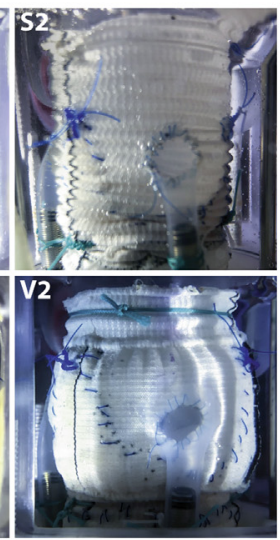

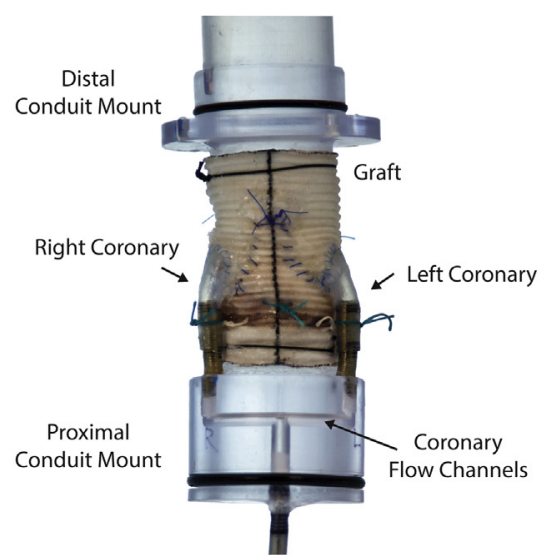

B
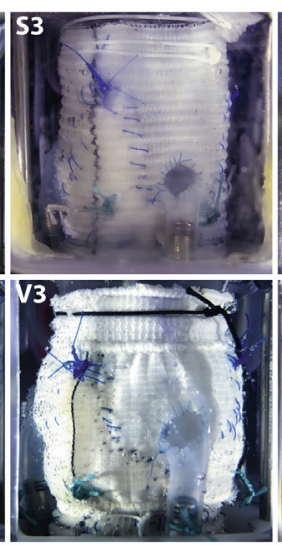
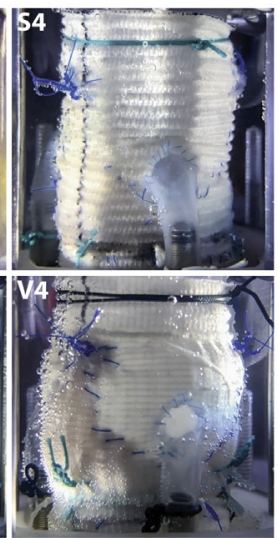
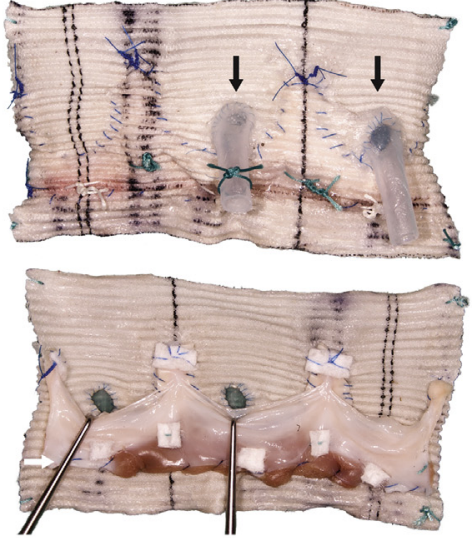

C

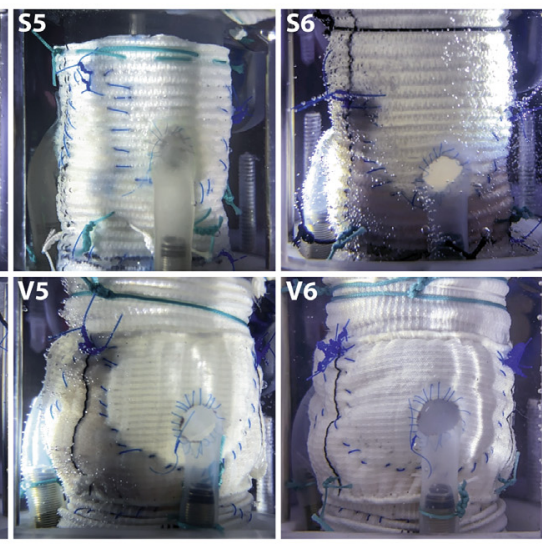

FIGURE 2. A, Left heart simulator components. B, Valve-sparing root replacement model with coronary circulation ports noted. C, Panoramic view of sample valve-sparing root conduit opened along the left/noncommissure with external view (top) showing silicone coronary tubes (black arrows) and coronet-shaped hemostatic second suture line and internal view (bottom) highlighting the subannular suture line (white arrow) sealing the left ventricular outflow tract cuff and proximal graft. D, Side-by-side comparison of grafts in each group, showing appropriately placed commissures at uniform heights. $S$, Straight; $V$, Valsalva.

For calibration, a size 27 bioprosthetic valve (St Jude Trifecta; Abbott, Lake Bluff, Ill) sewn into a 28-mm Dacron graft (Gelweave; Vascutek Terumo, Renfrewshire, Scotland) was affixed to the simulator as described in the following 2 sections. The pump was programmed to generate an effective stroke volume of $70 \mathrm{~mL}$ per beat at 70 beats per minute. We titrated peripheral resistance and compliance to generate a mean arterial pressure of $100 \mathrm{~mm} \mathrm{Hg}(120 / 80 \mathrm{~mm} \mathrm{Hg})$ at $5 \mathrm{~L} / \mathrm{min}$ cardiac output. We used a waveform with an approximately $50 \%$ systolic duration to better match in vivo conditions. ${ }^{27}$ Pressure transducers and flow meters were zeroed before trials, and the baseline valve was reinstalled between experiments to reduce drift.

\section{Model Aortic Root With Coronary Circulation}

To create a VSARR model, we 3D-printed cartridges to fit into an aortic conduit mount (ViVitro). The cartridges had barbed ends securing test grafts proximally and distally, and contained 4-mm inside diameter flow channels connecting to the mock coronary circulation (Figure 2, B). The coronary flow channels attached to the graft through segments of silicone tubing anastomosed to coronary neoostia that were created in the grafts. The coronary circulation was exteriorized at the level of the aortic root and passed through a flow meter, pressure transducer, compliance assembly, and adjustable resistance valve before returning to the venous reservoir. These parameters were adjusted to generate physiologic coronary hemodynamics; compliance and impedance were tuned with the baseline valve to generate $225 \mathrm{~mL} / \mathrm{min}$ of coronary blood flow with $5 \mathrm{~L} / \mathrm{min}$ cardiac output at $100 \mathrm{~mm} \mathrm{Hg}$ mean arterial pressure. Parameters remained constant throughout trials and were verified with frequent recalibration.

\section{Conduit Preparation}

Test conduits were prepared from 28-mm straight woven polyester grafts and 28-mm VGs (Vascutek Terumo). Conduits were trimmed to $4.5 \mathrm{~cm}$, with a $1-\mathrm{cm}$ annular cuff. Using a $4.8-\mathrm{mm}$ punch, coronary neo-ostia were made $10 \mathrm{~mm}$ above the annulus in the respective sinuses. A cautery pen was used to melt the edges of the holes to prevent fraying, expanding the diameter to approximately $5 \mathrm{~mm}$. Silicone tubing (4-mm inside diameter, $6-\mathrm{mm}$ outside diameter) was anastomosed to the grafts end-to-side with 6-0 polypropylene suture (Figure 2, $C$, top). An ostial diameter of $5 \mathrm{~mm}$ followed by luminal reduction to $4 \mathrm{~mm}$ is consistent with human coronary anatomy. ${ }^{28}$

Fresh porcine hearts (Yorkshire) were procured, including only hearts with aortic annular diameters of $25 \pm 2 \mathrm{~mm}$, ensuring similar annular diameters between the SG and VG groups $(25.0 \pm 1.4$ vs $25.7 \pm 0.8$; $P=.341)$. The aortic roots were dissected free and removed by circumferentially transecting the LVOT $1 \mathrm{~cm}$ below the sinus nadirs. We 

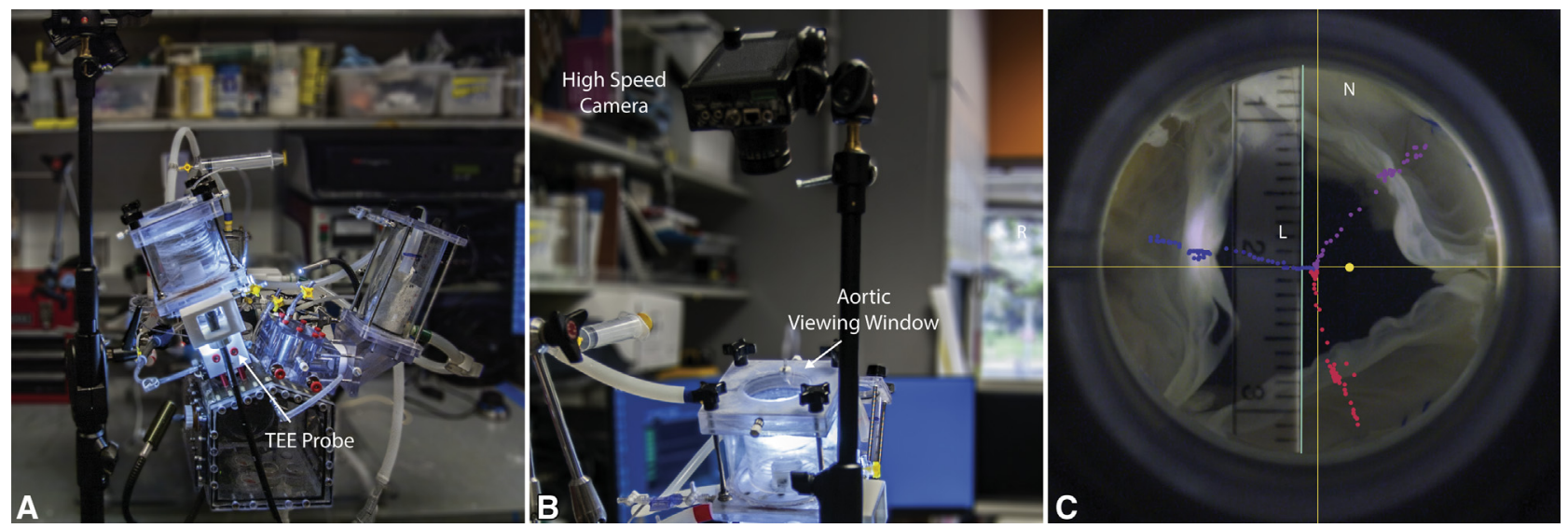

FIGURE 3. A, Built-in ports allow for passage of a transesophageal echocardiography (TEE) probe for valve imaging and doppler measurements. B, Highspeed photography of the aortic valve was obtained through a viewing port built into the top of the aortic chamber. C, Videometric analysis was performed to plot displacement and velocity of each of the aortic valve cusps. $L$, Left coronary cusp; $N$, noncoronary cusp.

carefully skeletonized the roots to avoid damaging the valve. Valves were randomly reimplanted into either SGs $(n=6)$ or VGs $(n=6)$ using a dual suture line reimplantation technique previously described (Figure 2, $C$ ). The annular suture level, intercommissural distances, commissural heights, coaptation height, free margin length, cusp height, and coronary button positions in the unpressurized grafts were standardized. Only symmetrical valves were used to avoid cusp prolapse and the necessity for correction. A single surgeon trained in the procedure reimplanted all valves. A composite of each graft is shown to demonstrate appropriate commissural height, proper technique, and standardization (Figure 2, D).

\section{Hemodynamic Data Collection and Analysis}

Conduits were mounted, the system was filled with $37^{\circ} \mathrm{C}$ saline, deaired, and ran for 10 minutes before rezeroing sensors. Aortic, ventricular, atrial, and coronary pressure tracings, along with aortic and coronary flow tracings, were recorded. Data were imported into MATLAB (version R2018A; MathWorks, Natick, Mass) for analysis and plotting. Using direct hemodynamic measurements, effective orifice area (EOA) was calculated using the Gorlin equation. ${ }^{29}$

\section{Echocardiography}

A Philips iE33 system with an X7-2T transesophageal echocardiography (TEE) probe and S5-1 transthoracic probe (Koninklijke Philips NV, Amsterdam, The Netherlands) was used for echocardiography. The simulator was designed with built-in ports for direct TEE instrumentation, allowing for excellent image quality without acoustic gel (Figure 3, A). For views not obtainable with TEE, we used the transthoracic probe through specially designed ports. Continuous and pulsed-wave Doppler was obtained from the ventricular port and M-mode views from the aortic root port. Leaflet apposition length was measured as the distance the leaflet free margins coapt, and coaptation height was measured as the distance from the basal ring to the distal tip of the coapted leaflets at end-diastole. Analysis and interpretation was performed using the iE33 on-board software. Using echocardiographic parameters, EOA was calculated using the continuity equation.

\section{High-Speed Videography}

To analyze leaflet and graft motion, we used high-speed videography at 1057 frames per second with $1280 \times 1024$ resolution (Chronos 1.4, Kron Technologies, Burnaby, British Columbia, Canada). Video was recorded from an en face perspective to analyze leaflet motion, and laterally to analyze graft motion (Figure 3, B). Using motion analysis software (Logger
Pro, Vernier, Beaverton, Ore), leaflet displacements were mapped and cusp opening and closing velocities calculated (Figure 3, $C$, and Video 1). Aortic valve area was measured by tracing the leaflet free margins and calculating geometric area in frames at maximal valve opening.

\section{Statistical Analysis}

The primary end point was a difference in regurgitant fraction. The standard deviation was expected to be $2.5 \%{ }^{30}$ We had $80 \%$ power to detect a difference of $4 \%$ at an $\alpha$ of 0.05 with 6 per group. All analyzed variables were normally distributed and homoscedastic (verified using the Shapiro-Wilk test and Levene test, respectively). Continuous variables are reported as mean \pm standard deviation. Two-tailed unpaired

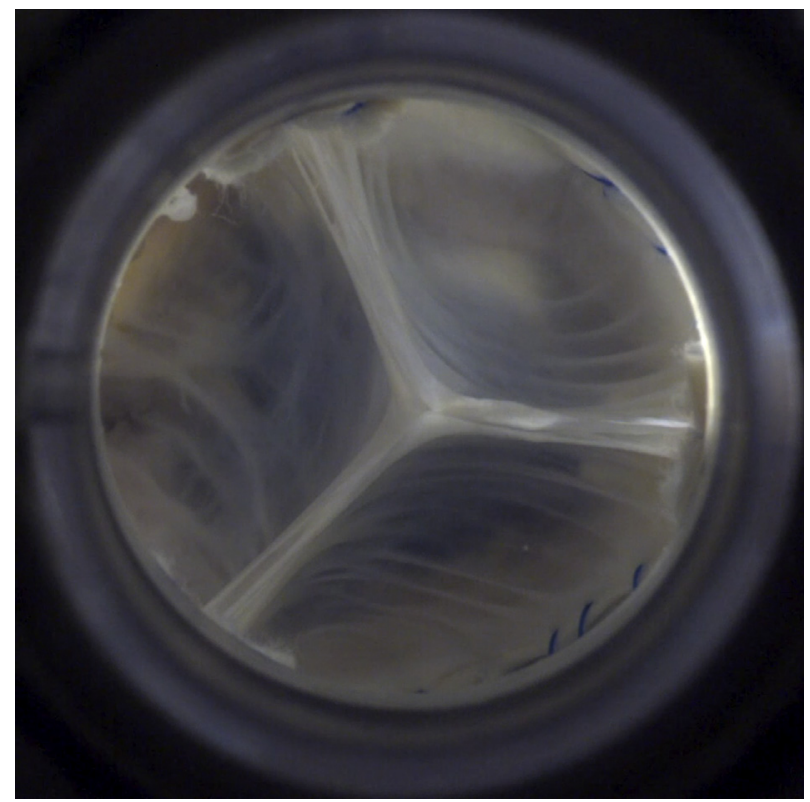

VIDEO 1. Sample overlay of videometric analysis with high-speed videography at 1057 frames per second (down-sampled to minimize file size). Video available at: https://www.jtcvs.org/article/S0022-5223(18) 32965-9/fulltext. 


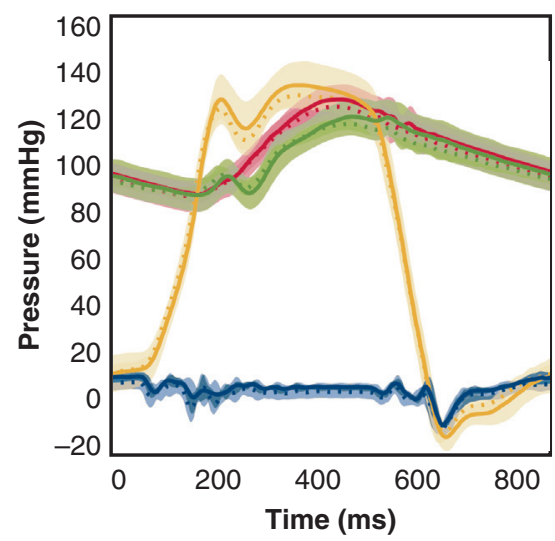

A
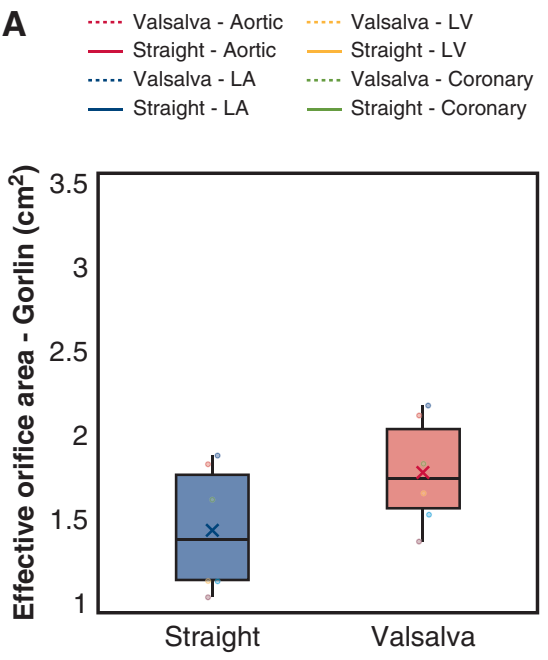

D

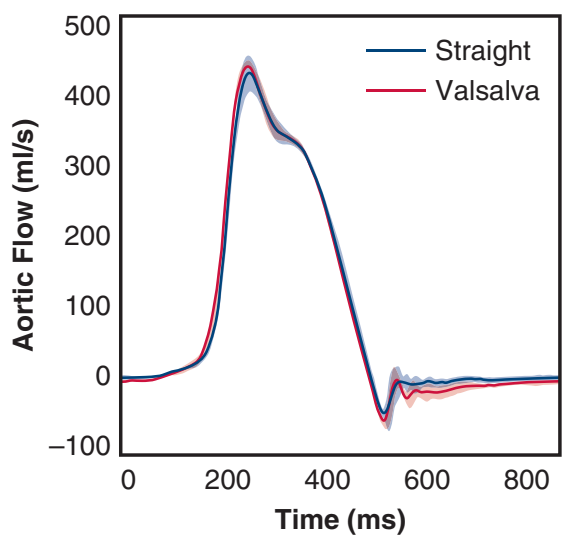

B

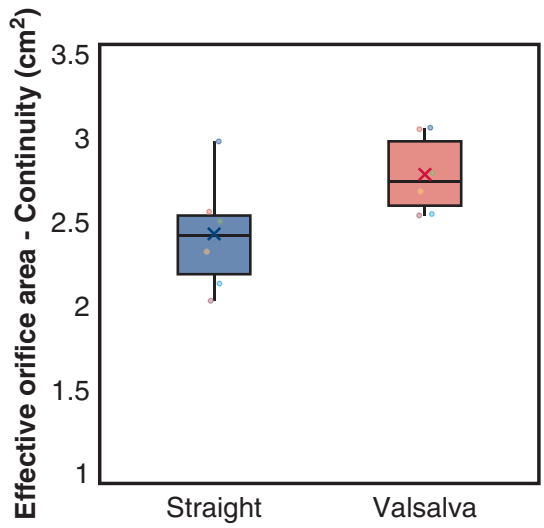

E

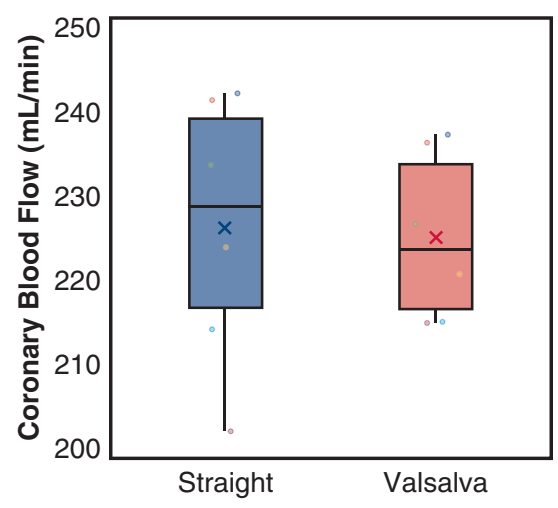

C

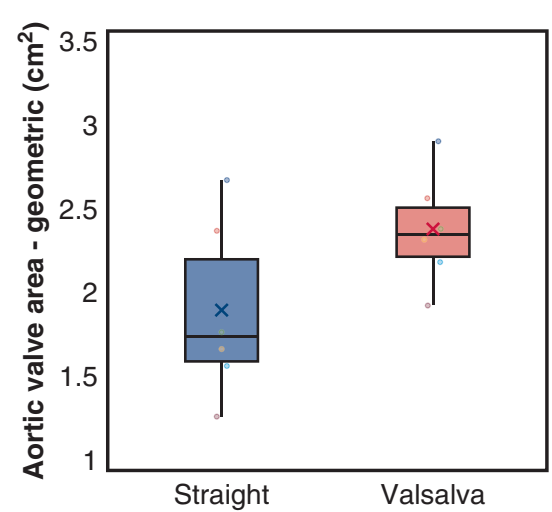

$\mathbf{F}$

FIGURE 4. A, Mean pressure tracings with no significant difference between the straight graft group (solid line) and Valsalva group (dotted line). B, Mean flow tracing from the 2 experimental groups showing no significant difference. For (A) and (B), shaded areas represent standard deviation. C, No significant difference in mean coronary blood flow was observed. D-F, Effective orifice area was also similar between groups using various calculation methods. C-F, Box denotes upper and lower quartiles, solid horizontal line represents the median, whiskers represent maximum and minimum values, the $x$ represents the mean, and data points are plotted for reference.

Student $t$ tests were used to compare continuous variables between 2 groups. A $P$ value of $<.05$ was considered statistically significant.

\section{RESULTS}

\section{Hemodynamics and Coronary Blood Flow Are}

\section{Similar Between Valsalva and Straight Conduits}

No significant differences in aortic, left ventricular, coronary, or left atrial pressure tracings were evident between groups (Figure 4, A), and aortic flow was also similar (Figure 4, $B$ ). Relevant hemodynamic parameters are summarized in Table 1 . We observed a trend toward higher left ventricular pressures in SGs with correspondingly higher measured transvalvular gradients $(11.4 \pm 7.9$ vs $6.4 \pm 4.2 \mathrm{~mm} \mathrm{Hg} ; P=.2)$, although these differences were not statistically significant. Mean coronary blood flow was not significantly different between SGs and VGs $(225 \pm 16 \mathrm{~mL} / \mathrm{min}$ vs $224 \pm 10 \mathrm{~mL} / \mathrm{min} ; P=.88$; Figure $4, C$ ).
EOA trended toward being smaller in SGs calculated using the Gorlin equation $\left(1.5 \pm 0.4 \mathrm{~cm}^{2}\right.$ vs $1.8 \pm 0.3 \mathrm{~cm}^{2} ; P=.12$; Figure $\left.4, D\right)$ as well as with the continuity equation $\left(2.4 \pm 0.3 \mathrm{~cm}^{2}\right.$ vs $2.8 \pm 0.2 \mathrm{~cm}^{2}$; $P=.056$; Figure $4, E)$. Aortic valve area calculated using videometric analysis was $1.9 \pm 0.5 \mathrm{~cm}^{2}$ in the $\mathrm{SG}$ group and $2.4 \pm 0.3 \mathrm{~cm}^{2}$ in the $\mathrm{VG}$ group $(P=.1$; Figure 4, F).

\section{Valves Reimplanted Into SGs Experience Lower Regurgitant Fractions, Decreased Radial Commissural Displacement, and Increased Coaptation Height}

Flow tracing integrations revealed lower regurgitation in the SG group. Closing volume was similar $(1.61 \pm 0.55 \mathrm{vs}$ $1.89 \pm 0.58 ; P=.40)$, however, SGs experienced lower leakage rates $(3.29 \pm 2.51$ vs $11.17 \pm 3.05 \mathrm{~mL} / \mathrm{s}$; $P<.001)$ and volumes $(1.28 \pm 1.06$ vs $4.53 \pm 1.13$; 
TABLE 1. Hemodynamic, echocardiographic, and videometric characteristics

\begin{tabular}{|c|c|c|c|}
\hline & Straight & Valsalva & $P$ value \\
\hline \multicolumn{4}{|l|}{ Hemodynamics } \\
\hline Mean porcine aortic annular diameter, $\mathrm{mm}$ & $25.0 \pm 1.4$ & $25.7 \pm 0.8$ & .341 \\
\hline Heart rate, beats per minute & $70 \pm 0$ & $70 \pm 0$ & 1.000 \\
\hline Mean arterial pressure, $\mathrm{mm} \mathrm{Hg}$ & $102.8 \pm 2.8$ & $101.2 \pm 1.6$ & .235 \\
\hline Systolic pressure, $\mathrm{mm} \mathrm{Hg}$ & $123.2 \pm 3.6$ & $120.4 \pm 2.0$ & .122 \\
\hline Diastolic pressure, $\mathrm{mm} \mathrm{Hg}$ & $84.4 \pm 2.5$ & $83.7 \pm 2.2$ & .660 \\
\hline Cardiac output, L/min & $5.0 \pm 0.1$ & $4.9 \pm 0.1$ & .105 \\
\hline Effective stroke volume, $\mathrm{mL}$ & $74.4 \pm 1.4$ & $75.5 \pm 1.6$ & .208 \\
\hline Pump stroke volume, $\mathrm{mL}$ & $109.8 \pm 0.1$ & $109.9 \pm 0.1$ & .268 \\
\hline Mean transaortic pressure, $\mathrm{mm} \mathrm{Hg}$ & $11.4 \pm 7.9$ & $6.4 \pm 4.2$ & .200 \\
\hline Aortic forward flow time, $\mathrm{s}$ & $0.43 \pm 0.03$ & $0.39 \pm 0.02$ & .020 \\
\hline Effective orifice area, $\mathrm{cm}^{2}$ (Gorlin equation) & $1.5 \pm 0.4$ & $1.8 \pm 0.3$ & .116 \\
\hline Aortic valve regurgitant fraction, $\%$ & $3.9 \pm 1.2$ & $8.5 \pm 2.0$ & .001 \\
\hline Aortic valve leakage rate, $\mathrm{mL} / \mathrm{s}$ & $-3.29 \pm 2.51$ & $-11.17 \pm 3.05$ & .001 \\
\hline Aortic valve leakage volume, $\mathrm{mL}$ & $-1.28 \pm 1.06$ & $-4.53 \pm 1.13$ & $<.001$ \\
\hline Aortic valve closing volume, $\mathrm{mL}$ & $-1.61 \pm 0.55$ & $-1.89 \pm 0.58$ & .402 \\
\hline Transaortic leakage energy loss, $\mathrm{mJ}$ & $16.0 \pm 14.1$ & $55.9 \pm 14.5$ & .001 \\
\hline Mean coronary blood flow, $\mathrm{mL} / \mathrm{min}$ & $225 \pm 16$ & $224 \pm 10$ & .882 \\
\hline Mean graft compliance, $\mathrm{mL} / \mathrm{mm} \mathrm{Hg}$ & $1.9 \pm 0.1$ & $2.1 \pm 0.2$ & .117 \\
\hline \multicolumn{4}{|l|}{ Echocardiographic parameters } \\
\hline Maximum gradient, $\mathrm{mm} \mathrm{Hg}$ & $11.8 \pm 2.8$ & $12.5 \pm 1.6$ & .625 \\
\hline Mean gradient, $\mathrm{mm} \mathrm{Hg}$ & $5.3 \pm 1.0$ & $4.8 \pm 0.8$ & .360 \\
\hline Effective orifice area, $\mathrm{cm}^{2}$ (continuity equation) & $2.4 \pm 0.3$ & $2.8 \pm 0.2$ & .055 \\
\hline M-mode rapid valve opening velocity, $\mathrm{cm} / \mathrm{s}$ & $26.4 \pm 4.0$ & $28.1 \pm 5.1$ & .545 \\
\hline M-mode rapid valve closing velocity, $\mathrm{cm} / \mathrm{s}$ & $10.9 \pm 2.1$ & $19.2 \pm 2.1$ & $<.001$ \\
\hline Leaflet apposition length, $\mathrm{mm}$ & $6.9 \pm 0.8$ & $5.3 \pm 0.4$ & .001 \\
\hline Coaptation height, mm & $13.1 \pm 0.8$ & $9.3 \pm 0.5$ & $<.001$ \\
\hline Videometric analysis & $0.0 \pm 0.0$ & $0.0 \pm 0.0$ & $<.001$ \\
\hline Aortic valve area, $\mathrm{cm}^{2}$ (geometric area) & $1.9 \pm 0.5$ & $2.4 \pm 0.3$ & .096 \\
\hline Peak radial intercommissural separation, $\%$ & $4.1 \pm 2.0$ & $13.1 \pm 2.7$ & $<.001$ \\
\hline \multicolumn{4}{|l|}{ Opening } \\
\hline Left coronary cusp mean opening velocity, $\mathrm{cm} / \mathrm{s}$ & $20.5 \pm 3.7$ & $28.8 \pm 1.9$ & .001 \\
\hline Right coronary cusp mean opening velocity, $\mathrm{cm} / \mathrm{s}$ & $18.0 \pm 3.9$ & $27.1 \pm 2.5$ & .001 \\
\hline Noncoronary cusp mean opening velocity, $\mathrm{cm} / \mathrm{s}$ & $18.8 \pm 3.2$ & $26.1 \pm 2.0$ & .001 \\
\hline Average mean leaflet opening velocity, $\mathrm{cm} / \mathrm{s}$ & $19.1 \pm 1.9$ & $27.3 \pm 1.1$ & $<.001$ \\
\hline Relative leaflet opening force & $1.0 \pm 0.3$ & $2.6 \pm 0.4$ & .017 \\
\hline \multicolumn{4}{|l|}{ Closing } \\
\hline Left coronary cusp mean closing velocity, $\mathrm{cm} / \mathrm{s}$ & $6.9 \pm 1.6$ & $11.7 \pm 2.4$ & .003 \\
\hline Right coronary cusp mean closing velocity, $\mathrm{cm} / \mathrm{s}$ & $9.7 \pm 1.2$ & $11.9 \pm 1.8$ & .030 \\
\hline Noncoronary cusp mean closing velocity, $\mathrm{cm} / \mathrm{s}$ & $7.7 \pm 2.4$ & $14.0 \pm 1.6$ & $<.001$ \\
\hline Average mean leaflet closing velocity, $\mathrm{cm} / \mathrm{s}$ & $8.1 \pm 0.7$ & $12.5 \pm 0.5$ & $<.001$ \\
\hline Relative leaflet closing force & $1.0 \pm 0.3$ & $3.1 \pm 0.1$ & $<.001$ \\
\hline
\end{tabular}

Data are presented as mean \pm SD.

$P<.001)$. Consequently, regurgitant fraction was lower in SGs $(3.9 \pm 1.3 \%$ vs $8.5 \pm 2.0 \% ; P<.001$; Figure $5, A)$ leading to lower transaortic energy loss $(16.0 \pm 14.1$ vs $55.9 \pm 14.5 \mathrm{~mJ} ; P<.001$; Figure 5, B). Videometric analysis of graft motion revealed that valves reimplanted into SGs experience nearly 3 times lower peak radial intercommissural separation than valves in VGs $(4.1 \pm 2.0 \%$ vs $13.1 \pm 2.7 \% ; P<.001$; Figure $5 C$; Video 2). These differences notwithstanding, average compliance was similar (SG: $1.9 \pm 0.1$ vs $\mathrm{VG}$ $2.1 \pm 0.2 \mathrm{~mL} / \mathrm{mm} \mathrm{Hg} ; P=.12$; Figure $5, D$ ). Despite taking great care to standardize free margin length and coaptation level when sewing valves in the unpressurized state, echocardiographic analysis-in the pressurized state-showed that valves reimplanted into VGs had shorter leaflet apposition lengths $(5.3 \pm 0.4$ vs $6.9 \pm 0.8 \mathrm{~mm} ; P=.001$; Figure $5, E)$ and lower coaptation heights $(9.3 \pm 0.5$ vs $13.1 \pm 0.8 \mathrm{~mm} ; P<.001$; Figure $5, F)$. From videometric analysis, the influence of radial displacement on coaptation is shown (Video 3; corresponding to graft V1 in Figure 2, D). Despite stabilization of the tops of the commissures in the distal tubular VG segment, the lower 


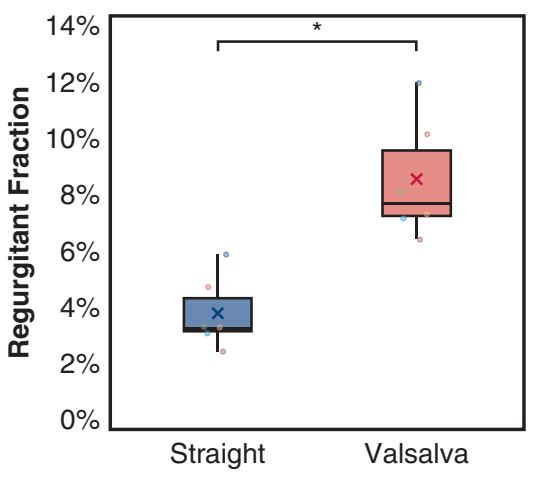

A

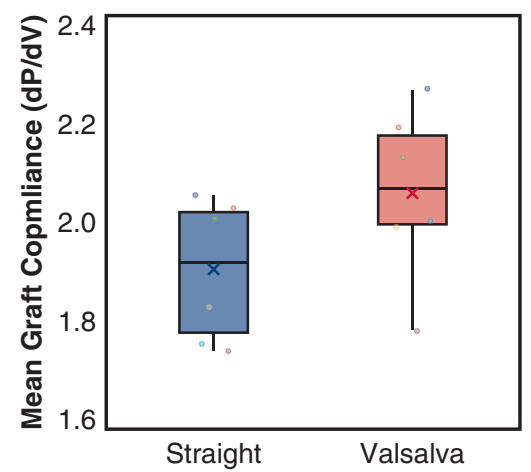

D

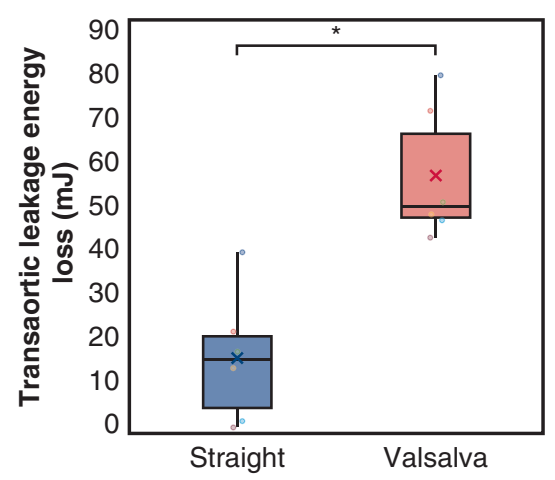

B

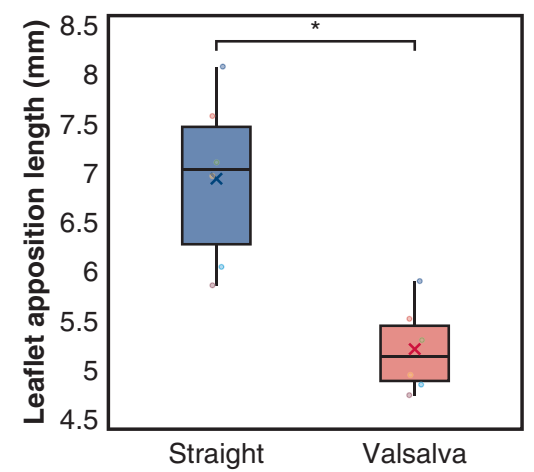

E

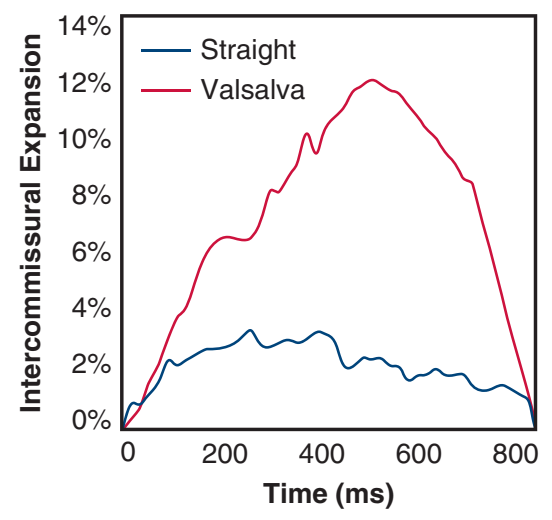

C

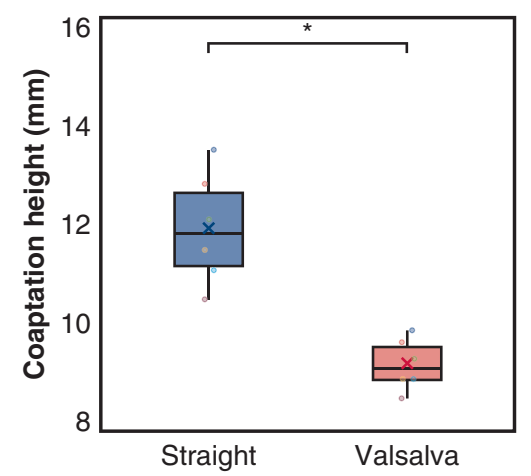

$\mathbf{F}$

FIGURE 5. A, Regurgitant fraction was significantly lower in the $\mathrm{SG}$ group $(3.9 \pm 1.2 \%$ vs $8.5 \pm 2.0 \% ; P=.001)$. B, Consequently, transaortic leakage energy loss was also lower in the SG group $(16.0 \pm 14.1 \mathrm{vs} 55.9 \pm 14.5 \mathrm{~mJ} ; P=.001)$. C, Valves sewn into straight grafts showed significantly lower average peak intercommissural expansion than valves sewn into Valsalva grafts $(4.1 \pm 2.0 \%$ vs $13.1 \pm 2.7 \% ; P<.001)$ measured using high-speed videometry. $\mathrm{D}$, Mean graft compliance was similar between grafts. E and F, Echocardiography showed that valves reimplanted in straight grafts have significantly longer leaflet apposition lengths $(6.9 \pm 0.8 \mathrm{~mm}$ vs $5.3 \pm 0.4 \mathrm{~mm} ; P<.001$; E) as well as higher heights of coaptation $(13.1 \pm 0.8 \mathrm{vs} 9.3 \pm 0.5 \mathrm{~mm} ; P<.001 ; \mathrm{F})$, which might explain lower regurgitation. For (B-F), box denotes upper and lower quartiles, solid horizontal line represents the median, whiskers represent maximum and minimum values, the $x$ represents the mean, and data points are plotted for reference.

portions of the commissural posts and leaflet hinge regions are pulled outward, decreasing leaflet coaptation and causing visible leakage.

\section{Leaflet Opening and Closing Velocities Are Significantly Reduced in SGs Resulting in Decreased Leaflet Forces}

Leaflet opening and closing velocities (Table 1) were calculated using M-mode echocardiography as previously described. ${ }^{2}$ Opening velocity was similar between groups, however, closing velocities were significantly lower in SGs $(10.9 \pm 2.1$. vs $19.2 \pm 2.1 \mathrm{~cm} / \mathrm{s} ; P<.001$; Figure 6 , $A$ ). To corroborate these measurements, videometric analysis was performed to map leaflet displacement (Figure 6, B), from which velocity could be derived for all 3 leaflets simultaneously (Table 1 ). The average leaflet opening velocity for valves reimplanted into SGs was significantly lower than those in VGs $(19.1 \pm 1.9$ vs 27.3 $\pm 1.1 \mathrm{~cm} / \mathrm{s} ; P<.001$; Figure $6, C$ ). Average leaflet closing velocity was also significantly lower in the SG group $(8.1 \pm 0.7$ vs $12.5 \pm 0.5 \mathrm{~cm} / \mathrm{s} ; P<.001$; Figure $6, D)$. From these measurements, we derived acceleration and calculated relative forces (assuming equal cusp and fluid column masses), showing that valves reimplanted into SGs endure 2.6 times lower leaflet opening forces and 3.1 times lower closing forces $(P<.05$ and $P<.01$, respectively; Figure 6, $D$ and $E)$.

\section{DISCUSSION}

Valve-sparing root replacement was first described nearly 30 years ago, and we are still striving to perfectly recreate nature. Valsalva grafts demonstrate outstanding long-term outcomes with freedom from reoperation greater than $90 \%$ at over 10 years. Mimicking the native sinuses of Valsalva is assumed to be better than omitting them completely, but this might not be true, as this study suggests. Likely, this is because some elements of the VG design do not match the anatomy of the native aortic sinuses. The aortic valve 


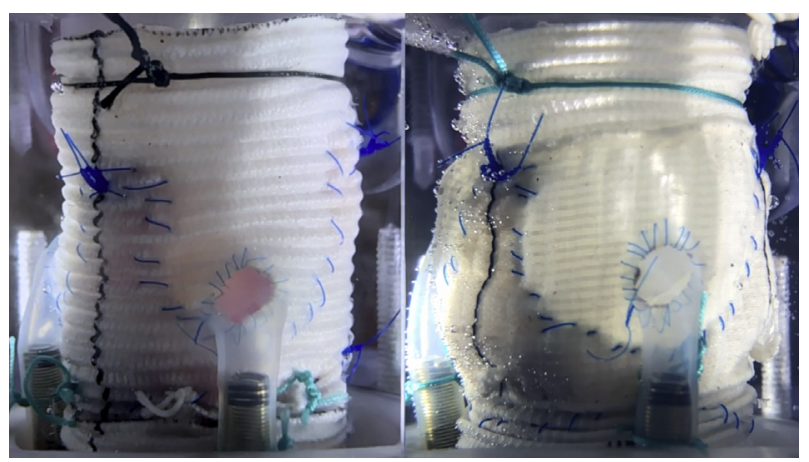

VIDEO 2. Side-by-side high-speed videography of straight and Valsalva grafts (down-sampled to minimize file size). Video available at: http://www.jtcvs.org.

commissures should be directly in line with the annulus, in a cylindrical conformation. By forcing the commissures into a spherical shape, radial distortion might impact valve kinematics.

Radial commissural displacement with decreased leaflet coaptation is the likely mechanism for higher regurgitation observed in VGs, and the effect is compounded by significantly higher peak intercommissural expansion from the elastic longitudinally-corrugated VG skirt. A potential benefit of this approach is a larger EOA, although this might not be worth the risk as SGs provide adequate valve area.

Additionally, radial commissural distortion has a magnifying effect on leaflet forces, whereas maintaining the commissures in their native cylindrical conformation mitigates these changes. As shown, leaflets of valves reimplanted into rigid straight grafts experience significantly lower opening and closing velocities and accelerations. As a result, forces exerted on these leaflets are up to 3 times lower in SGs than in VGs. Although we might only speculate how durability is influenced from the results of this ex vivo study, we believe that lower forces may lead to reduced wear on the cusps of valves reimplanted into straight grafts. Interestingly, our study contradicts some existing studies in which leaflet velocities were measured in vivo using echocardiography, which showed decreased leaflet velocities in VGs. ${ }^{2,11,12}$ In these studies, it is not clearly specified when studies were obtained, only that the highest-quality images available were used from either intraoperative TEE or postoperative follow-up. Because of the confounding effects of cardiopulmonary bypass, perioperative volume shifts, and postoperative medications, the use of postbypass aortic cusp velocities might not be reliable and might explain why our M-mode measurements showed higher leaflet closing velocities in the VG group when hemodynamic variables were held constant.

Furthermore, with the effect of shadowing commonly observed when performing ultrasound through Dacron,

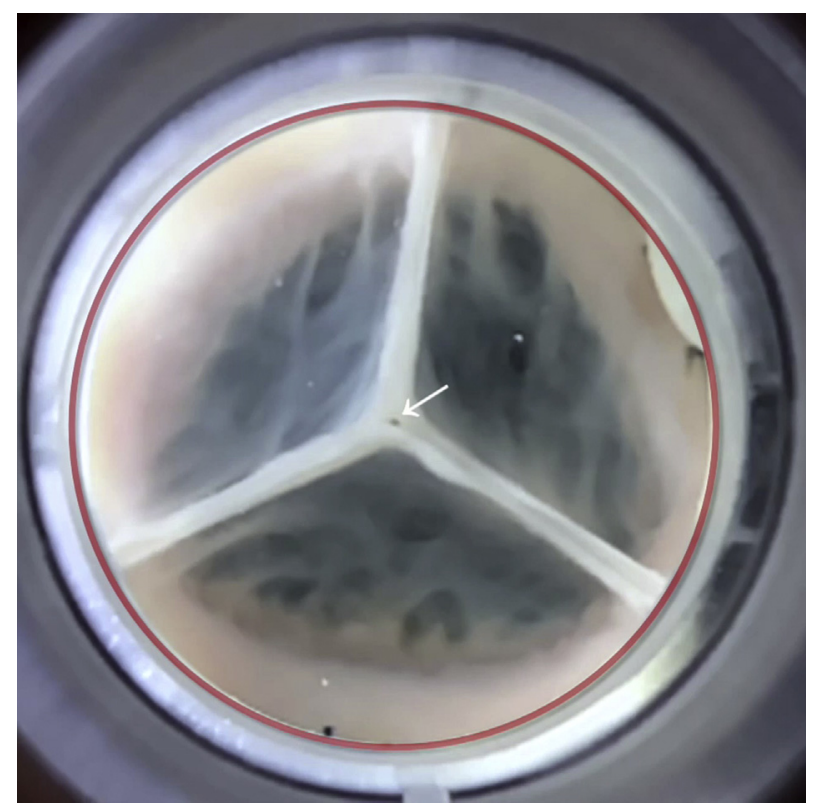

VIDEO 3. Transverse view of aortic valve sewn inside of Valsalva graft (corresponding to conduit V1 in Figure 2,D) showing that despite stabilization of the tops of the commissures in the distal tubular VG segment, the mid and lower portions of the commissural posts and leaflet hinge regions are pulled outward radially, decreasing leaflet coaptation and causing visible leakage (white arrow). Video available at: http://www.jtcvs.org.

the sensitivity of M-mode velocimetry is suboptimal. Velocity is measured on just 1 leaflet in the imaging plane, which might not be truly perpendicular to the plane of motion, introducing error. Thus, we measured leaflet velocity directly with high-speed photography, which showed significantly lower velocities in all 3 leaflets in SG repairs. The spatial $(0.1 \times 0.1 \mathrm{~mm})$ and temporal resolution $(1057$ frames per second) of high-speed videography is also higher than that of other modalities (including echocardiography and magnetic resonance imaging), making it ideal for measuring kinematics. Videography is not as useful for visualizing flow, particularly with opaque objects. Fourdimensional magnetic resonance imaging, echo-particle image velocimetry, Doppler, and computational fluid dynamics can generate excellent flow visualizations, and many groups have studied the influence of sinuses on aortic root fluid dynamics. $5,31-40$

These studies clearly show that the sinuses of Valsalva critically influence the behavior of the aortic valve and root. Although we did not detect any meaningful differences in coronary blood flow, valve hemodynamics, or flow profiles between the conduits we compared, the benefits of neosinus creation might be overshadowed by the consequences of commissural distortion. Other graft designs or modifications may help mitigate these consequences. The CARDIOROOT graft (Maquet Cardiovascular, LLC, 


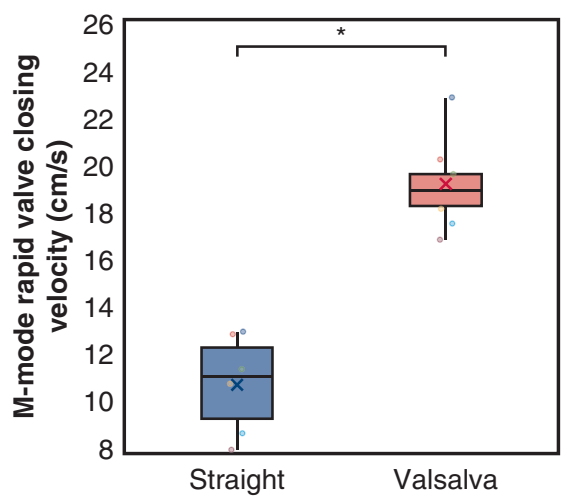

A

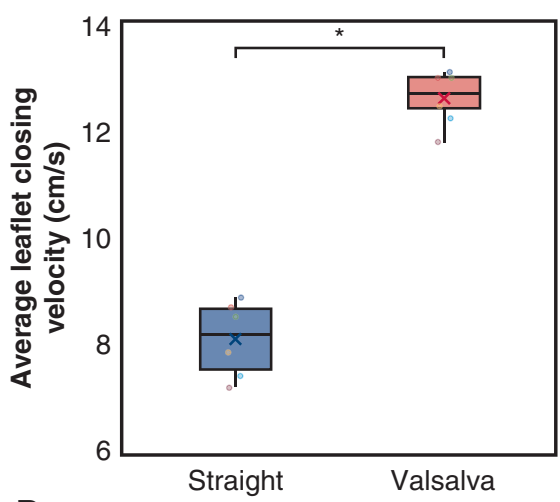

D
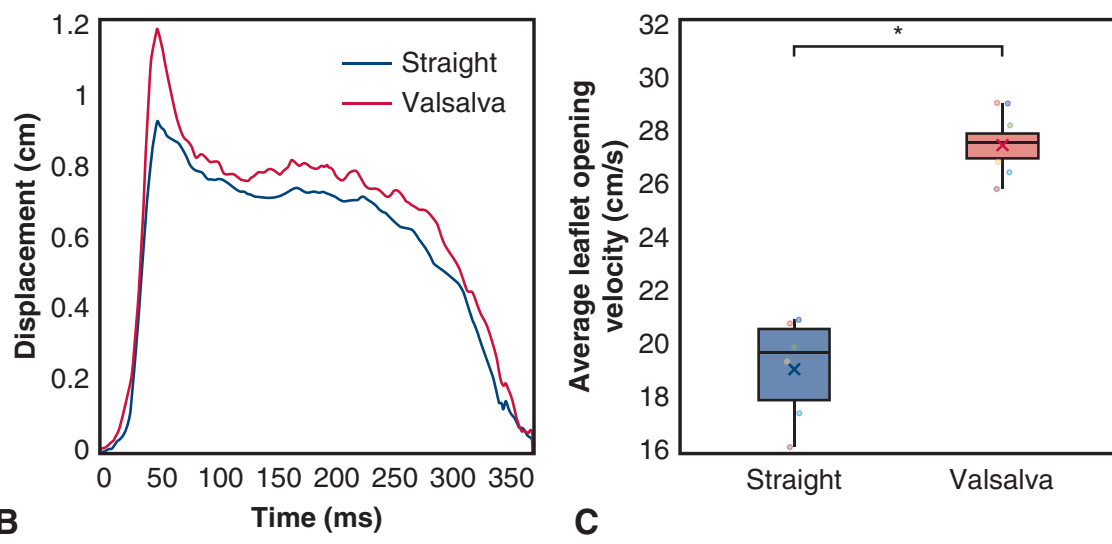

C

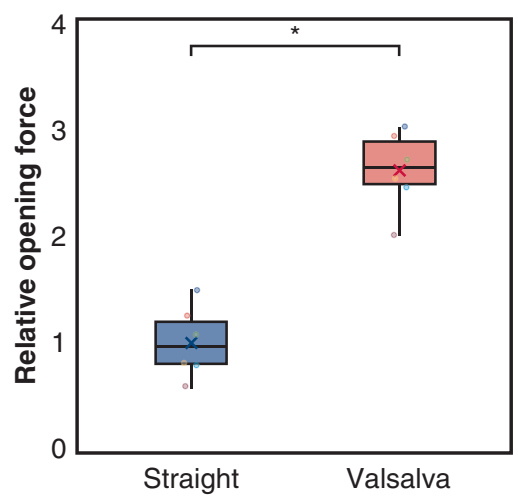

E

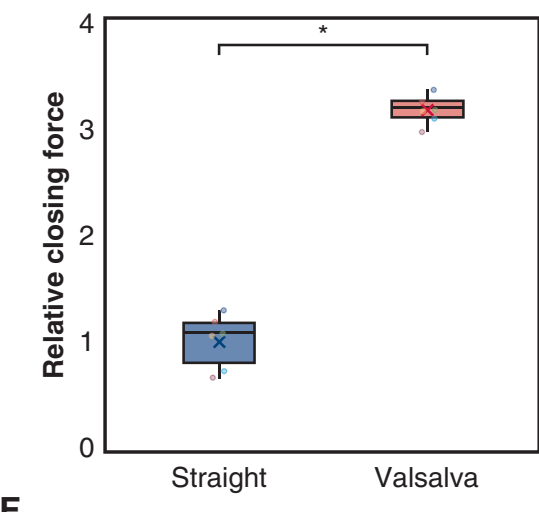

FIGURE 6. A, M-mode echocardiography was also used to assess leaflet velocities, which showed significantly lower rapid valve closing velocities in the straight graft group $(10.8 \pm 2.1 \mathrm{~cm} / \mathrm{s}$ vs $19.2 \pm 2.1 \mathrm{~cm} / \mathrm{s} ; P<.001)$. B, To corroborate echocardiography measurements, we used high-speed photographic data to assess valve leaflet and graft mechanics. Mean leaflet displacement was plotted for each individual leaflet (shown here as an aggregate for demonstration purposes). C and D, By taking the derivatives of cusp displacements for each graft, mean velocities were calculated, showing significantly lower mean opening (C) and closing velocities (D) in the straight graft group $(19.1 \pm 1.9 \mathrm{~cm} / \mathrm{s} \mathrm{vs} 27.3 \pm 1.1 \mathrm{~cm} / \mathrm{s} ; P<.001$ and $8.1 \pm 0.7 \mathrm{~cm} / \mathrm{s} \mathrm{vs} 12.5 \pm 0.5 \mathrm{~cm} / \mathrm{s}$; $P<.001$, respectively). E and F, As a result, leaflets of valves sewn into straight grafts experienced significantly lower relative opening forces (E, $2.6 \pm 0.4$; $P<.05)$ and relative closing forces $(3.1 \pm 0.1 ; P<.01)$ than those in Valsalva grafts. For (B-F), box denotes upper and lower quartiles, solid horizontal line represents the median, whiskers represent the maximum and minimum values, the $x$ represents the mean, and data points are plotted for reference.

Wayne, NJ) is similar to the VG but has a more tapered distal sinus, although it retains the circular transverse profile of the VG. A new graft (Uni-Graft W SINUS; B. Braun, Berlin, Germany) that maintains cylindrical commissural position but possesses sinus-like outpouchings is available in Europe and might be promising. ${ }^{41}$ However, patients often present with variations from the "textbook" $120^{\circ}$ intercommissural spacing, particularly those with connective tissue disorders and bicuspid aortopathies. Various iterations and "back-table" modifications of the VSARR procedure have been developed using an oversized graft necked down or attached to a smaller graft distally to recreate the sinuses; whether these techniques are subject to radial commissural distortion is unclear. ${ }^{9,10}$ Alternatively, a technique to tailor commercially available SGs to possess neosinuses without radial commissural displacement through anticommissural plication has been described, and on cardiac magnetic resonance studies appeared to mimic native aortic geometry and flow profiles. $^{40,42,43}$ Further study of these techniques and grafts will provide further information on ideal conduit choice and are currently under way.

As with any experiment, our study does have limitations. Although the porcine aortic root is anatomically similar to the human root, there are several differences including coronary ostia height, although this is not relevant to our model. ${ }^{44,45}$ Relative cusp sizes also vary between humans and pigs, with the right cusp being largest and noncoronary cusp smallest in pigs, whereas in humans the noncoronary cusp is largest and left smallest. ${ }^{45,46}$ However, overall annular dimensions, cusp depth, commissural height, and leaflet thickness are similar, making the porcine root the best animal model available. ${ }^{44,45}$ Separating the valve from the more muscular porcine LVOT can be challenging and might affect leaflet kinematics. ${ }^{47}$ The increased muscular support in heterografts has important ramifications during chronic use, such as increased calcification. However, its effects 
on acute study parameters can be minimized with meticulous debulking of excess muscle. In addition, our model does not replicate the complex vortices generated by the left ventricle, and we use saline rather than a non-Newtonian blood analogue; both limitations can be overcome by future in vivo experiments. ${ }^{31,39}$ Nevertheless, an ex vivo model provides a controlled and reproducible environment to study and compare the biomechanics of 2 surgical techniques to a degree not possible in vivo.

\section{CONCLUSIONS}

Using a novel ex vivo model of VSARR, we studied the differences between VGs and SGs to elucidate biomechanical mechanisms that may influence clinical performance. Although VGs accurately model aortic root geometry longitudinally, the native aortic valve commissures are displaced radially, whereas straight grafts stabilize the commissures cylindrically. Maintaining the commissures in their native cylindrical conformation results in lower intercommissural separation, preserved coaptation, lower regurgitant fraction, decreased cusp velocities, and ultimately lower leaflet forces, which might translate to improved long-term durability. Newer graft designs and innovative techniques to create neosinuses without radial commissural displacement might optimize hemodynamics without compromising structural geometry. Further investigation of these novel grafts, as well as other established operative techniques for recreating native sinuses of Valsalva, is required before definitive conclusions regarding optimal conduit choice are made.

\section{Conflict of Interest Statement}

Authors have nothing to disclose with regard to commercial support.

The authors thank Jeffrey E. Cohen, MD, Justin M. Farry, BSE, Haley J. Lucian, BS, John W. MacArthur Jr, MD, and Daniel von Bornstädt, $\mathrm{MD}$, for their valuable contributions.

\section{References}

1. David TE, Feindel CM. An aortic valve-sparing operation for patients with aortic incompetence and aneurysm of the ascending aorta. J Thorac Cardiovasc Surg. 1992;103:617-21; discussion: 622.

2. Leyh RG, Schmidtke C, Sievers HH, Yacoub MH. Opening and closing characteristics of the aortic valve after different types of valve-preserving surgery. Circulation. 1999;100:2153-60.

3. David TE. Aortic valve haemodynamics after aortic valve-sparing operations. Eur J Cardiothorac Surg. 2012;41:788-9.

4. Bellhouse BJ, Bellhouse FH, Reid KG. Fluid mechanics of the aortic root with application to coronary flow. Nature. 1968;219:1059-61.

5. Kvitting JP, Ebbers T, Wigström L, Engvall J, Olin CL, Bolger AF. Flow patterns in the aortic root and the aorta studied with time-resolved, 3-dimensional, phase-contrast magnetic resonance imaging: implications for aortic valve-sparing surgery. J Thorac Cardiovasc Surg. 2004;127:1602-7.

6. Grande-Allen KJ, Cochran RP, Reinhall PG, Kunzelman KS. Re-creation of sinuses is important for sparing the aortic valve: a finite element study. J Thorac Cardiovasc Surg. 2000;119:753-63.
7. Thubrikar MJ, Nolan SP, Aouad J, Deck JD. Stress sharing between the sinus and leaflets of canine aortic valve. Ann Thorac Surg. 1986;42:434-40.

8. Miller DC. Valve-sparing aortic root replacement in patients with the Marfan syndrome. J Thorac Cardiovasc Surg. 2003;125:773-8.

9. David TE, Armstrong S, Ivanov J, Feindel CM, Omran A, Webb G. Results of aortic valve-sparing operations. J Thorac Cardiovasc Surg. 2001;122:39-46.

10. Demers P, Miller DC. Simple modification of "T. David-V" valve-sparing aortic root replacement to create graft pseudosinuses. Ann Thorac Surg. 2004;78: 1479-81.

11. De Paulis R, De Matteis GM, Nardi P, Scaffa R, Bassano C, Chiariello L. Analysis of valve motion after the reimplantation type of valve-sparing procedure (David I) with a new aortic root conduit. Ann Thorac Surg. 2002;74: 53-7.

12. De Paulis R, De Matteis GM, Nardi P, Scaffa R, Buratta MM, Chiariello L. Opening and closing characteristics of the aortic valve after valve-sparing procedures using a new aortic root conduit. Ann Thorac Surg. 2001;72:487-94.

13. Weltert L, De Paulis R, Scaffa R, Maselli D, Bellisario A, D'Alessandro S Re-creation of a sinuslike graft expansion in Bentall procedure reduces stress at the coronary button anastomoses: a finite element study. J Thorac Cardiovasc Surg. 2009;137:1082-7.

14. De Paulis R, Chirichilli I, Scaffa R, Weltert L, Masellin D, Salica A, et al. Longterm results of the valve reimplantation technique using a graft with sinuses. $J$ Thorac Cardiovasc Surg. 2016;151:112-9.

15. David TE, David CM, Feindel CM, Manlhiot C. Reimplantation of the aortic valve at 20 years. J Thorac Cardiovasc Surg. 2017;153:232-8.

16. Settepani F, Bergonzini M, Barbone A, Citterio E, Basciu A, Ornaghi D. Reimplantation valve-sparing aortic root replacement with the Valsalva graft: what have we learnt after 100 cases? Interact Cardiovasc Thorac Surg. 2009;9: 113-6.

17. Settepani F, Szeto WY, Pacini D, De Paulis R, Chiariello L, Di Bartolomeo R, et al. Reimplantation valve-sparing aortic root replacement in Marfan syndrome using the Valsalva conduit: an intercontinental multicenter study. Ann Thorac Surg. 2007;83:S769-73; discussion: S785.

18. Xu L, Gao F, Li P, Xu Y, Liu S, You B, et al. Early and midterm outcomes of the VSSR procedure with De Paulis valsalva graft: a Chinese single-center experience in 38 patients. J Cardiothorac Surg. 2015;10:167.

19. Price J, Magruder JT, Young A, Grimm JC, Patel ND, Alejo D, et al. Long-term outcomes of aortic root operations for Marfan syndrome: a comparison of Bentall versus aortic valve-sparing procedures. J Thorac Cardiovasc Surg. 2016;151: 330-6.

20. Kari FA, Beyersdorf F, Rylski B, Stephens EH, Russe M, Siepe M. David I reimplantation procedure for aortic root replacement in Marfan patients: medium-term outcome. Interact Cardiovasc Thorac Surg. 2014;19:743-8.

21. Mignosa C, Di Stefano S, Mazzamuto M, Degno N, Mariani C, Romeo A, et al. Midterm follow-up of the reimplantation technique in patients with relatively normal annulus: is David I still a clinically valid option? J Thorac Cardiovasc Surg. 2014;148:1334-40.

22. Shrestha M, Baraki H, Maeding I, Fitzner S, Sarikouch S, Khaladj N, et al. Long-term results after aortic valve-sparing operation (David I). Eur J Cardiothorac Surg. 2012;41:56-61; discussion: 61.

23. Leontyev S, Trommer C, Subramanian S, Lehmann S, Dmitreieva Y, Misfeld M, et al. The outcome after aortic valve-sparing (David) operation in 179 patients: a single-centre experience. Eur J Cardiothorac Surg. 2012;42:261-6; discussion: 266.

24. Kvitting JP, Kari FA, Fischbein MP, Liang DH, Beraud A-S, Stephens EH, et al. David valve-sparing aortic root replacement: equivalent mid-term outcome for different valve types with or without connective tissue disorder. J Thorac Cardiovasc Surg. 2013;145:117-26. 127.e1.

25. David TE. Aortic valve sparing in different aortic valve and aortic root conditions. J Am Coll Cardiol. 2016;68:654-64.

26. David TE. Additional anatomic information on the aortic root. J Thorac Cardiovasc Surg. 2015;149:408-10.

27. Bazan O, Ortiz JP. Duration of systole and diastole for hydrodynamic testing of prosthetic heart valves: comparison between ISO 5840 standards and in vivo studies. Braz J Cardiovasc Surg. 2016;31:171-3.

28. Dodge JT, Brown BG, Bolson EL, Dodge HT. Lumen diameter of normal human coronary arteries. Influence of age, sex, anatomic variation, and left ventricular hypertrophy or dilation. Circulation. 1992;86:232-46.

29. Gorlin R, Gorlin SG. Hydraulic formula for calculation of the area of the stenotic mitral valve, other cardiac valves, and central circulatory shunts. I. Am Heart J. 1951;41:1-29. 
30. Al-Atassi T, Toeg HD, Jafar R, Sohmer B, Labrosse M, Boodhwani M. Impact of aortic annular geometry on aortic valve insufficiency: insights from a preclinical, ex vivo, porcine model. J Thorac Cardiovasc Surg. 2015;150:656-64.e1.

31. Oechtering TH, Hons CF, Sieren M, Hunold P, Hennemuth A, Huellebrand M, et al. Time-resolved 3-dimensional magnetic resonance phase contrast imaging (4D flow MRI) analysis of hemodynamics in valve-sparing aortic root repair with an anatomically shaped sinus prosthesis. J Thorac Cardiovasc Surg. 2016;152:418-27.e1.

32. Galea N, Piatti F, Lau C, Sturla F, Weltert L, Carbone I, et al. 4D flow characterization of aortic blood flow after valve sparing root reimplantation procedure. J Vis Surg. 2018;4:95.

33. Gaudino M, Piatti F, Lau C, Sturla F, Weinsaft JW, Weltert L, et al. Aortic flow after valve sparing root replacement with or without neosinuses reconstruction. J Thorac Cardiovasc Surg. July 27, 2018 [Epub ahead of print].

34. Galea N, Piatti F, Sturla F, Weinsaft JW, Lau C, Chirichilli I, et al. Novel insights by 4D Flow imaging on aortic flow physiology after valve-sparing root replacement with or without neosinuses. Interact Cardiovasc Thorac Surg. 2018;26:957-64.

35. Salica A, Pisani G, Morbiducci U, Scaffa R, Massai D, Audenino A, et al. The combined role of sinuses of Valsalva and flow pulsatility improves energy loss of the aortic valve. Eur J Cardiothorac Surg. 2016;49:1222-7.

36. Conti CA, Votta E, Della Corte A, Del Viscovo L, Bancone C, Cotrufo M, et al. Dynamic finite element analysis of the aortic root from MRI-derived parameters. Med Eng Phys. 2010;32:212-21.

37. Yap CH, Saikrishnan N, Tamilselvan G, Yoganathan AP. Experimental measurement of dynamic fluid shear stress on the aortic surface of the aortic valve leaflet. Biomech Model Mechanobiol. 2012;11:171-82.

38. Yap CH, Saikrishnan N, Tamilselvan G, Yoganathan AP. Experimental technique of measuring dynamic fluid shear stress on the aortic surface of the aortic valve leaflet. J Biomech Eng. 2011;133:061007.
39. Markl M, Draney MT, Miller DC, Levin JM, Williamson EE, Pelc NJ, et al Time-resolved three-dimensional magnetic resonance velocity mapping of aortic flow in healthy volunteers and patients after valve-sparing aortic root replacement. J Thorac Cardiovasc Surg. 2005;130:456-63.

40. Liu X, Weale P, Reiter G, Kino A, Dill K, Gleason T, et al. Breathhold time-resolved three-directional MR velocity mapping of aortic flow in patients after aortic valve-sparing surgery. J Magn Reson Imaging. 2009;29:569-75.

41. Richardt D, Karluss A, Schmidtke C, Sievers HH, Scharfschwerdt M. A new sinus prosthesis for aortic valve-sparing surgery maintaining the shape of the root at systemic pressure. Ann Thorac Surg. 2010;89:943-6.

42. Gleason TG. New graft formulation and modification of the David reimplantation technique. J Thorac Cardiovasc Surg. 2005;130:601-3.

43. David TE. Sizing and tailoring the Dacron graft for reimplantation of the aortic valve. J Thorac Cardiovasc Surg. 2005;130:243-4.

44. Wang C, Lachat M, Regar E, von Segesser LK, Maisano F, Ferrari E. Suitability of the porcine aortic model for transcatheter aortic root repair. Interact Cardiovasc Thorac Surg. 2018;26:1002-8.

45. Sands MP, Rittenhouse EA, Mohri H, Merendino KA. An anatomical comparison of human pig, calf, and sheep aortic valves. Ann Thorac Surg. 1969;8:407-14.

46. Sim EK, Muskawad S, Lim CS, Yeo JH, Lim KH, Grignani RT, et al. Comparison of human and porcine aortic valves. Clin Anat. 2003;16:193-6.

47. Crick SJ, Sheppard MN, Ho SY, Gebstein L, Anderson RH. Anatomy of the pig heart: comparisons with normal human cardiac structure. JAnat. 1998;193:105-19.

Key Words: aorta, valve-sparing aortic root replacement, valve-sparing surgery, conduit, in vitro modeling, ex vivo modeling, leaflet velocity, coronary blood flow 